\title{
Understanding Limits from a Social Ecological Perspective
}

\author{
Teresa Cerratto Pargman \\ Stockholm University \\ Postbox 7003 \\ 16407 Kista \\ Sweden \\ tessy@dsv.su.se
}

\author{
Somya Joshi \\ Stockholm University \\ Postbox 7003 \\ 16407 Kista \\ Sweden \\ somya@dsv.su.se
}

\begin{abstract}
The latest developments in the field of HCI have given rise to an increasing interest in issues pertaining to global warming, resource depletion and environmental degradation. Concern about such issues has contributed to give shape to the design space of Sustainable HCI (SHCI); a space whose boundaries are at times blurred. On the one hand, some, design "sustainable" information technology based on visions of the world that do not really question limits to continuous economic growth and, on the other hand, others embrace the design of information technology from stances that acknowledges limits (i.e. economic, ecological, energetic). This paper introduces the perspective of social ecology into SHCI. This perspective provides us with a core set of principles that makes us situate computing at the intersection of physical (natural) and moral (human) qualities of our human environment systems. As such it confronts us with choices to be made in the challenging years to come and invites us to argue about the very purpose of information technology in a world of limitations.
\end{abstract}

\section{Keywords}

Resilience, sustainable development, material-ecological and socio-semiotic dimensions, transactions, multi-forms of capital.

\section{INTRODUCTION}

Our understanding of "limits" is firstly grounded in the results reported in "The Limits to Growth" [24] published in 1972 by the Club of Rome, pointing out the planetary limits in relation to the continued growth of the global economy. Secondly, our thinking about "limits" is also related to perceived contradictions in the current HCI "normal" scientific paradigm [19], which we believe are signaling its boundaries.

Meadows et al. report [24] stated clearly that unchanged, infinite global growth of population, pollution, food production and resource depletion will certainly result in the collapse of the economic system and population. But, following [30], it also concluded about the possibility of altering these growth trends establishing "a condition of ecological and economic stability that is sustainable far into the future. The state of the global equilibrium could be designed so that the basic material needs of each person on earth are satisfied and each person has an equal

LIMITS '15, June 15-16, 2015, Irvine, California, USA. opportunity to realize his individual potential” [p.551].

These insights resonate with an understanding of a possible sustainable development in a world within limits, which have motivated us to engage with sustainability issues in the field of HCI. The concept of sustainable development [i.e. Brundtland report] understood here as qualitative development that is decoupled from (quantitative) continuous economic growth, connects with the following HCI issues we believe are compelling to study: How do we build systems that are in line with current understanding of the earth's finite natural resources? How do we design them to catalyze and sustain social change (i.e. going toward a more sustainable and resilient way of living)? These issues and other central questions have been introduced and developed within the Sustainable HCI (SHCI) literature [4, 39, 25, $11,31,35,2,9,29,14,38,28]$. This pioneering body of research work has drawn on theoretical and applied developments that can be related to third wave HCI [6]. They have on the one hand, touched upon key issues related to our everyday practices and culture and, on the other hand, they have overflowed third wave HCI boundaries as these conceptual and applied developments are not only focused on the cultural, emotional, pragmatic or culturalhistorical levels of human experience [6], but also are deeply concerned by environmental [27, 28, 1], socio-political [13], political economy [26], social sustainability [5], ecological [36] and ethical concerns [18]. These developments are progressively elaborating on a plethora of dimensions that are redefining the focus and object of research within HCI whilst inquiring the very final purpose of the HCI research field in relation to current global societal demands and imminent urges. More precisely, we believe that latest research developments of SHCI research indicate an interest into the development and design (or undesign) of technologies relying less on instrumental purposes of efficiency connected with corporate profit [25] (motivated by research paradigms grounded in the belief of infinite economic growth) and relying more on volitional and value-laden aspects underlying people's use of technologies [8]. These exotic volitional and value-laden aspects also relate to an increasing body of research concerned by working with design as a means to address moral concerns [21, 10,3] and conceptualize how design theory intersects design practice for the construction of the publics $[22,20,12]$. These strands of HCI research, bringing together sustainability and moral issues as well as civic participation, are here seen as, "anomalies" within the accepted "normal" HCI paradigm [19]. In particular, these anomalies point to a contradiction between i) a majority of HCI research contributing to the technical and social progress of society through the development of new technologies and applications that aim at 
increasing consumption and thus waste, pollution and impacting the global environment in an irreversible way. And ii) a minority of research work inclined to rethinking human computation from world's visions that are more in line with contemporary moral and environmental conundrums. This contradiction, we believe, reflects a healthy tension in a field under development. A tension between thinking, designing and building technology for a world without economic and ecological limitations (and primarily regulated by a continuous growth of finance capital), and thinking, designing and building technology for a world with finite natural resources. That is, one that is concerned by the implications of such limits on the sustainability of our societies, as well as on the ecosystem as a whole. Such a tension points thus at scientific understandings operating at different ontological and epistemological levels that move us toward a paradigm shift in HCI. Moreover, such tensions provoke us to ask what type of contributions we, as HCI researchers, should aim for; whilst they also force us to reflect on the visions we have of the world we inhabit. From such a broad understanding of "limits" (to economical growth and within $\mathrm{HCI}$ ), this paper intends to contribute to the discourse on sustainability whilst bringing to the fore a socio-ecological perspective into the discussion.

\section{INTRODUCING THE SOCIAL ECOLOGICAL PERSPECTIVE}

Our interest in the socio ecology perspective [37,23] is in part due to its systemic and holistic approach of sustainability of humanenvironments. And, more in particular, to its understanding of how planetary limits can be thought of in terms of both naturalecological and constructed (socio-semiotic). Sustainability and in particular resilience of our environments (which has seldom mentioned in the SHCI discourse) are thus analyzed taking into account both dimensions. According to [37], "Maintaining resilience through adaptability is an important prerequisite for ensuring the longer-term sustainability of a human-environment system" [p. 2]. The notion of resilience, provides us thus with a frame to examine the intricacies and imbrication of the multiple types of relationships people entertain with the earth, the others, themselves and their own modes of consumption and production of resources. From such an understanding, Stokols et al. [37] consider resilience of human-environment systems as a qualitative attribute that emerges from multiple relationships between the natural-ecological and the constructed world. These relationships are specifically distinguished in terms of transactions and multicapital formation. These are two kinds of relationships that might be of interest to SHCI as they provide us with a terminology to talk about qualitative changes that emerge from various relationships that constitute sustainability and resilience of our environment. More specifically, by transactional relationships, Stokols et al. [37] refer to continuous, bidirectional and mutually influencing relationships occurring between both materialecological (i.e. natural) and social-semiotic dimensions (i.e. meanings, values, moral judgments). It is within these relationships, "active or missing, supportive or perverse" [23], questions pertaining to the fate of technology in a future of resource scarcity are compelling to think about. In particular, the concept of transactional processes introduces the idea that there are exchanges among diverse assets, resources and actors that are tangled in the activation, formation and mobilization of multiple (not equivalent) forms of capital (i.e. financial, natural, humanmade environment, technological, social, human and moral capital). As such, questions about the raison d'etre of computing in a world with limitations can be interesting to situate as part of a broader context that includes different types of exchanges among natural and semiotics resources (i.e. that in turn mobilize multi forms of capital). We see thus computing (i.e. information technology) as part of a great technological capital humanity disposes of for engaging in transactions that might lead us to increase resilience of our environment. For example, decrement in one form of capital (i.e. people's realization of decrement of natural resources related to peak oil and climate change) activates people to make use of technology to disseminate information on movements sharing information about alternative ways of living (i.e. the simplicity collective ${ }^{1}$ ) or developing mobile technology for introducing fairness (i.e. Fairphone ${ }^{2}$ movement) into a competitive market. The idea of situating computing as a capital able to be transacted among others teases out current HCI understandings of what changes are viable or not vis-à-vis the resilience of our human-environment systems.

With the aim to better specify the contribution of a social ecological perspective we introduce four core principles and discuss them in relation to SHCI.

\subsection{Four core principles of social ecology and their relation to the field of Sustainable HCI}

The following principles provides us with conceptual tools to broaden up current understandings of sustainability issues in SHCI, and to reflect on the role that computing can play at the heart of transactional processes [37,23].

\subsection{1 "Social ecology highlights the multidimensional structure of human environments". [37 p. 3].}

This principle encompasses an understanding of the multifaceted nature of human activity (i.e. social, cultural) that calls for an integrative analysis. That is, an analysis able to provide a context for understanding how natural-ecological and socio-semiotic components affect each other and eventually change the human system and its individuals. In SHCI, Håkansson and Sengers [16] for instance, present a study of how families relate to sustainability issues from a holistic standpoint. Although the authors do not talk explicitly about multiple dimensions of families environment, we see clear connections between their critique to current work in SHCI (i.e. that has a tendency to approach or compartmentalize sustainability as primarily an environmental problem [16 p. 2728]) and the idea of approaching sustainable behaviors from a multifaceted understanding of how we connect to the environment. Another example is Peirce's and al. work on ecologies of practices [31] suggesting a focus on people's everyday practices as a relevant social cultural context for the understanding of how people relate to the environment. These studies show how social, cultural and material facets of human activities are deeply embedded in the larger context of ecology of life. Looking at others facets of human activities such as financial, political, ecological might also benefit SHCI in its exploration of sustainability issues in relation to computing. Moreover, conducting integrative analysis in SHCI will bring us to expand our interest for individual users to groups, communities and societies. In that respect, work conducted by $[13,16,1,12]$ points to this direction, through questions of scale [13]. Yet, the principle of multidimensionality of our environment systems also pays attention to sustainability and resilience as a "conjoint

\footnotetext{
${ }^{1} \mathrm{http}: / /$ simplicitycollective.com/acts-of-opposition

${ }^{2} \mathrm{http}: / / \mathrm{www}$.fairphone.com
} 
phenomena [operating] at different scales and approaching environmental settings in terms of their physical and social components (i.e. natural or built, material and semiotic qualities)[...]" [37 p.2]. Thus, we understand that introducing change into our human-environment involves reorganizing a multidimensional structure of our human systems. And that such reorganization operates at the intersection of physical-material and social-semiotic dimensions of such environment that coevolve. The idea of co-evolution of dimensions might be of interest to SHCI as it makes clear that our attempts to act and/or think about sustainability issues and resilience of our environment can not be regarded as simply a matter of taking the environment into account; it goes much deeper than that as the crux of the question lies in comprehending that "human beings are a coevolutionary part of the web of life" [30, p.562]. In that respect, we believe that our efforts to think about sustainability in relation to computing need for instance to consider that "sustainability" is neither an isolated attribute that a computer system can have -or not- nor an 'absolute standard' to be reached. On the contrary, sustainability is relational, dynamic, a moving target, which evolves over time and is performed from within; from a logic of transactions that the system in question is capable to make.

\subsection{2 "The interaction between multiple dimensions} of human activity (i.e. cultural, financial, ecological), is most deeply analyzed and understood in context"

$[23, p .2]$.

This principle resonates with SHCI work interested in studying individuals in groups, their practices in naturalistic contexts [3, $21,10,27]$. There is today an array of groups in need as well as a multitude of intentional communities that relate to a collapsing ${ }^{3}$ society on a daily basis. Immersed in real contexts, we will, as researchers and designers, be better grounded and equipped to figure out which potential changes our stored technological capital can trigger in order to assure the resilience of our human environments systems. Of special interest are for instance the study of contemporary social innovation movements that are striving toward alternative ways of living (e.g. grassroots initiatives, intentional communities like Transition Towns, the Transition Towns Movement, ecological ecovillages). These examples are loci of social experimentation, learning and innovation that are key for exploring questions revolving around the technology capital we dispose of and contribute to develop. To our knowledge there has not been much interest in understanding how information technology is used -or not used- in ecological communities. Although Nathan [27] has provided a compelling ethnographic analysis of two ecovillages that explicitly try to live by a core set of values and make use of information technology in their daily practices. In an ongoing study that looks at activities, practices and transactions within a Swedish ecovillage [7] we have, as Nathan [27] observed, that community members do not problematize the use of smart mobile phones, laptops (i.e. google documents, ecovillage's website, google groups, word, excel documents) and other types of information tools. On the contrary, they justify their sparing use as long as these technologies serve the development of the community and progress of the ecovillage. For instance, during a workshop, one of the members of the ecovillage under study [7] explained to us she relates to technology invoking a permaculture principle, "it is okay to use technology as a tool to start processes, new activities, but not for driving them". Such a statement reflects first the deep

\footnotetext{
${ }^{3}$ In Tomlinson's et al. sense [39].
}

embeddedness of technology in our contemporary life practices. Second, it translates the idea that the technological capital available in the community is valued in relation to other types of capital (i.e. human, social, moral etc.) mobilized when using technology in the community. Understanding which role our technological capital can play in a world with limits needs of contextual analysis of groups of people who have today voluntarily chosen to live within limits. As such contextual analysis of these communities are invaluable tools for understanding the purpose of using technology in a future of resource scarcity.

\subsection{3 "Social ecology, draws upon key concepts and assumptions from systems theory (e.g. interdependence, feedback, homeostasis) for the understanding of the interrelationships between social and physical systems and attaches great importance to describing how changes in one dimension are related to changes in another" [37, p.3]}

In SHCI, this principle may relate to the issue of obsolescence discussed in SHCI by [34] wherein they have stated that the rapid pace of technological development and the resulting replacement of end-user devices have unleashed an unprecedented surge of electronic waste upon our society. Likewise, these researchers outline some key indicators linked with obsolescence as engendered by technology interaction design. Of particular interest to our enquiry here, is for instance, the role of "slow design" suggested by [17]. This can be seen as not only addressing obsolescence through the design of products itself, but calling for a change in people's way of life in general. Even to the notion of "new luxury" as introduced by [4], where they point at luxury and material success as obstacles in tackling obsolescence since some consumers - commonly referred to as early adoptersalways like to have the most novel technology. New luxury might be leveraged to turn this traditional notion of material success and luxury against itself to promote a more sustainable behavior, for example, by shifting the societal paradigms such that owning a device for a longer amount of time becomes more desirable than buying a new one. These are examples of developments acknowledging a systemic thinking in SHCI that can also be linked to notions of re-use, common ownership, transferability, augmentation, and longevity - which are key obstacles that design can offer to fight obsolescence. But beyond a necessary systemic understanding of changes in our socio-ecological environment, what we found challenging in Stokols's et al. [37] perspective, is discerning that changes are not transformations or translations but transactions. Transactions in the sense that material or human resources are not fungible, as changes in one dimension are related to changes in another dimension. For example, in the study conducted in a Swedish ecovillage [7] we observed, through a content analysis performed on a corpus consisting of 850 e-mails sent by the community members during a year (i.e. May 2013April 2014), a series of transactions among multi-forms of capital [8]. More precisely, we noted that community members' use of information technology brought changes in the social and human capital of the community. For example, the community, since its foundation in 2009 , created a website displaying the progress of the ecovillage, informing about its open activities (i.e. tagging trees in the woods, fixing solar panels in the house ceilings, food cultivation, courses, etc.). The community which welcomes everyone through its website (people can register and automatically become a net-member or follower), counts today more than 300 members who voluntarily invest their time and 
physical work in the community when it is needed. As such the website has catalyzed a new social capital or "bridging capital" [33] in the sense that the ecovillage, (which only consists of only 18 families) can rely on a broader community for conducting heavy and time consuming activities while developing social ties with the larger community. Another example of transactions is that community members have developed a practice of taking and sending/posting pictures (via google groups) to the community as a way to report on changes or more exactly, achievements done collectively (i.e. "this is the photo of our first chicken!"). This practice involving the use of information technology ensures not only keeping members updated about community's achievements but also it creates "bonding capital" [33] among members. Moreover, the daily use of information technology by community members (i.e. most of the members do not permanently live in the ecovillage) has also brought changes in the human (intellectual) capital of the community as members exchange information (i.e. links, websites, YouTube films, articles, blogs, digital books) that has in part led, to material changes in the human-made environmental capital of the community (e.g. members have built dry toilettes, parts of buildings, chicken houses, fixed solar panels etc.). The configuration of these transactions involving relationships among social, human and technological capital can be seen as changes in the community that contribute to higher levels of its sustainability and resilience. In this respect, we can note that this particular community is making active choices (i.e. one the one hand they decide to grow their own food and on the other they use information technology to call for volunteers to prepare the land for cultivation or to disseminate, search information about principles of ecological farming) that acknowledge limits in their everyday life. Yet, the study of "how different forms of capital interact, support or conflict with each other" $[37, p .3]$ brings us to a deeper understanding of the very limitations of the "technology as solution paradigm". Material or human resources are not interchangeable or replaced by other new resources, but are through a complex process embedded in tensions, located at the intersection of natural and semiotic resources. In this respect, it is not absurd to argue that not all societal and environmental problems can be fixed via technological innovation alone as "there is no exchange rate that translates one type of resource into another" [37]. For instance, from other standpoints, the work presented by [2] as well as [32] point at limits of technology. The concept of transaction as understood in social ecology has thus implications on how we in SHCI can think about the delineation and understanding of the design space. We see it as an arena where computing can catalyze transactions between resources, assets and actors that in turn can increase the sustainability and resilience of human-environments systems.

\subsection{4 "Social-ecological analysis of human-} environment systems emphasizes a transdisciplinary action research orientation in which diverse knowledge cultures or epistemologies (e.g. academicdisciplinary; professional-practicioner; lay-citizen perspectives) are brought together for the understanding and improving the resilience and sustainability of people-environment systems" [37, p.3].

We understand this principle as an invitation to expand $\mathrm{HCI}$ borders and engage in a broader conversation with other disciplines. For instance perspectives from Political Economy
[26], Ecological Economy [23], Political Ecology [30], environmental justice and citizenship and governance [13], should be welcome to SHCI as they have traditionally elaborated on the relationships between ecology, economy and politics. We think these relationships are key for thinking about the purpose of our technologies in a world within limits. Broadening HCI limits resonates with Godman's [15] argument suggesting that HCI "can and should grapple with the institutional politics of transit, finance building construction and state regulation. Such a turn toward the political and infrastructural may require different theoretical orientations and pragmatic alliances" [p.7]. Yet, introducing a transdisciplinary action research orientation into SHCI would also open doors to other actors concerned by environmental and sustainability issues. Community activists, ecologists, politicians, policy makers, non-profits organizations and citizens could along with designers and researchers envision sustainable technocultural practices for resilient human-environment systems.

\section{CONCLUSION}

These core principles of social ecology provide us with a better understanding of how we belong to the ecology of our humanenvironment systems and how the ecology of our humanenvironment systems belongs to us. The central take-home message here is that: we are not only part of our environment but we are our environment and we evolve together with it and viceversa. Reflections about computing within limits might benefit from acknowledging that the relation between computing and the environment is 1) of a co-evolutionary nature, 2) presents a mutidimentional structure, 3 ) is reflected in transactions between material and semiotic resources, 4) is, analytically speaking, better grasped with contextual analysis of real contexts in a transdisciplinary action research orientation. Furthermore, these principles invite us to reflect on current epistemological and ontological boundaries in the field of HCI and on how they can be further expanded.

\section{REFERENCES}

1. Aoki, P.M.; Honicky, R.J.; Mainwaring, A.; Myers, C.; Paulos, E.; Subramanian, S. and Woodruff, A. A Vehicle for Research: Using Street Sweepers to Explore the Landscape of Environmental Community Action. In Proc. CHI'09 ACM (2009), 375-384.

2. Baumer, E.P.S. and Silberman, S.M. When the implication is not to design (technology), In Proc. CHI EA'11. ACM (2011), 2271-2274.

3. Bellotti, V., Caroll, J.M. and Kyungsik, H. Random acts of kindness: The intelligent and context-aware future of reciprocal altruism and community collaboration. In Proc. of CTS. IEEE (2013), 1-12.

4. Blevis, E., Makice, K., Odom, W., Roedl, D., Beck, C., Blevis, S., Ashok, A.: Luxury \& new luxury, quality \& equality. In Proc. DPPI '07, ACM Press (2007), 296-311.

5. Busse, D.; Blevis, E., Beckwith, R.; Bardzell, S.; Sengers, P.; Tomlinson, B.; Nathan, B. Social Sustainability: An HCI Agenda. In Proc. CHI EA'12. ACM Press (2010), 1151-1154.

6. Bödker, S. When second wave HCI meets third wave challenges. In Proc. NordiCHI 2006, ACM Press (2006), 1-8.

7. Cerratto-Pargman, T. Pargman, D and Nardi, B. (in preparation). Building sustainable capital in a connected ecovillage. 
8. Cerratto-Pargman, T. A European strand of Sustainable HCI? Position paper at NordiCHI 2014. (2014). Finland. http://tessy.blogs.dsv.su.se/publications/

9. Dillahunt, T. Toward a deeper understanding of sustainability within HCI. Workshop on Sustainability. What have we learned? At CHI'14. http://www.tawannadillahunt.com/

10. Dillahunt, T. Fostering social capital in economically distresses communities. In Proc. CHI'14, ACM Press (2014), 531-540.

11. DiSalvo, C., Sengers, P., and Brynjarsdòttir. Mapping the landscape of sustainable HCI, In Proc. CHI'10. ACM (2010), 1975-1984.

12. DiSalvo, C. Design and the Construction of Publics. Design Issues, Vol. 25, No. 1 (2009): 48-63.

13. Dourish, P. HCI and Environmental Sustainability: The Politics of Design and the Design of Politics. In Proc. DIS'10, ACM Press (2010),1-10.

14. Froehlich,J.; Findlater, L. and Landay, J. The design of ecofeedback technology. In Proc. CHI'10. ACM Press (2010). 1999-2008.

15.Godman, E. Three Environmental discourses in HumanComputer Interaction. In Proc. CHI EA’09. ACM Press (2009), $2535-2544$

16. Håkansson, M. and Sengers, P. Beyond Being Green: Simply Living Families and ICT. In Proc. CHI'13. ACM (2013). 27252734.

17. Hällnäs, 1. and Redström, J. Slow Technology. Designing for Reflection. Personal Ubiquitous Computing. 5, 3, 201-212.

18. Knowles, B., Blair, L. Coulton, P. and Lochrie, M. Rethinking Plan A for Sustainable HCI. In Proc.CHI'14. ACM Press (2014), 3593-3596.

19. Kuhn, T. La structure des révolutions scientifiques. Flammarion 1972.

20. Le Dantec, C.A., Christensen, J. E., Bailey, M., Farrell, R. G., Ellis, J. B., Danis, C., Kellogg, W. A. and Edwards, W. K. A Tale of Two Publics: Democratizing Design at the Margings. In Proc. DIS'10. ACM Press (2010), 11-20.

21. Le Dantec, C.A., Farrell, R. G., Christensen, J. E., Bailey, M., Ellis, J. B., Kellogg, W. A. and Edwards, W. K. Publics in Practice: Ubiquitous Computing at a Shelter for Homeless Mothers. In Proc. CHI'11 ACM Press (2011),1687-1696.

22. Le Dantec, C.A. Participation and Publics: Supporting Community Engagement. In Proc. CHI'12.ACM Press. (2012), $1351-1360$

23. Lejano, R. and Stokols, D. Social Ecology, Sustainability and Economics. Ecological Economics, 89 (2013), 1-6.

24. Meadows, D., Meadows, D., Randers, J. and Behrens III, W. Limits to Growth. Universe Books, 1972.
25. Nardi, B. The Role of Human Computation in Sustainability, or, Social Progress is Made of Fossil Fuels. In Handbook of Human Computation, New York, Springer, 2013.

26. Nardi, B. Draft.

27. Nathan, L. Ecovillages, sustainability and information tools: Ethnography of values, adaptation and tension. University of Washington. (2009).

28. Nathan, L., Friedman, B. and Hendry, D. Information system Design as catalyst: human Action and Environmental Sustainability. Interactions. ACM Press (2009), 6-11.

29. Pargman, D. and Raghavan, B. Rethinking sustainability in computing: from buzzword to non-negotiable limits. In Proc. NordiCHI'14. ACM Press (2014), 638-647.

30. Pezzoli, K. Sustianable development: A transdisciplinary overview of the literature. Journal of Environmental Planning and Management, 40:5 1997, 549-574.

31. Pierce, J., Strengers, Y., Sengers, P. and Bödker, S. Introduction to the Special issue on Practice-oriented approaches to sustainable HCI. ACM TOCHI. Volume 20, Issue 4. 2013.

32. Pierce, J. Undesigning Technology. In Proc. CHI'12. ACM Press (2012), 957-966.

33. Putnam, R. Bowling Alone :The collapse and revival of the American Community. Simon \& Schuster. New York. 2000.

34. Remy, C. and Huang, E. Addressing the Obsolescence of enduser devices: Approaches from the field of Sustainable HCI. ICT Innovations for Sustainability. Vol. 310. Springer 2015, 257-267.

35. Sengers, P., Boehner, K. and Knouf, N. Sustianable HCI meets Third Wave HCI: 4 Themes. Workshop at CHI'09. http://elainehuang.com/CHI-2009/p5-sengers.pdf

36. Silberman, S. and Tomlinson, B. Toward an Ecological Sensibility. In Proc.CHI'10 EA. ACM Press (2010), 3469-3474.

37. Stokols, D., Lejano, R. and Hipp, J. Enhancing the Resilience of Human-Environment Systems: a Social Ecological Perspective. Ecology and Society, 18(1), 7.(2013), 1-12.

38. Strengers, Y. Designing Eco-Feedback Systems for EverydayLife. In Proc.CHI'11. ACM Press (2011), 2135-2144.

39. Tomlinsson, B., Blevis, E., Nardi, B., Patterson, D., Silberman, $\mathrm{S}$, and Yuan, P. Collapse Informatics and practice: Theory, Method and Design. ACM TOCHI. Vol. 20. Issue 4.Article 24. 2013.

40. Turner, G. A comparison of the limits to growth with thirty years of reality. CSIRO Sustainable Ecosystems, Australia. 2008. 